\title{
Industrial Agglomeration and Pollution Emission
}

\author{
Wang Zhi \\ South China University of Technology, Panyu District, Guangzhou, Guangdong \\ 370431455@qq.com
}

\begin{abstract}
To study the relationship between industrial agglomeration and pollution emission, Fixed Effect Model is used to analyze the panel data of 21 prefecture-level cities in Guangdong Province from 2005 to 2014. It is found that industrial agglomeration has a negative external effect on the intensity of pollution discharge, and industrial agglomeration can reduce the emission intensity of pollution. The intensity of energy consumption has a positive external effect on pollution discharge, and the enterprises with high energy consumption increase the intensity of pollution discharge. The innovation of this paper lies in the analysis of the relationship between industrial agglomeration and environmental pollution from the perspective of pollution emission intensity.
\end{abstract}

Keyword: Industrial agglomeration, Pollution emission intensity, Environmental pollution

\section{Introduction:}

Guangdong Province in 2008 proposed the "vacate cage for birds," the double transfer strategy, that is, the traditional labor-intensive and high development costs of resource-intensive industries transfer to the east and west wings, to make room for undertaking and developing new industries. East, West, North is to undertake an important area of industrial transfer. After the implementation of industrial transfer policy, industrial relocation area to undertake industrial upgrading significantly enhance the degree of local economic development has brought sustained and rapid growth. However, with the rapid development of economy, the degree of industrial agglomeration continues to increase, and the environmental problems in industrial relocation areas are becoming more and more serious.

\section{Impact Mechanism of Industrial Agglomeration on Industrial Pollution Emission}

\subsection{Infrastructure sharing effect}

The degree of infrastructure perfection is an important factor in the choice of location and the formation of industrial agglomeration. It is also one of the external economic effects brought about by industrial agglomeration. Industry concentration of layout, industry enterprises can share the logistics, energy, environmental protection and other infrastructure and innovation infrastructure, thereby reducing the duplication of infrastructure to reduce energy consumption and pollution emissions.

\subsection{Intermediate input sharing effect}

Agglomeration area enterprises have a relationship between before and after the relationship between enterprises before and after the association is an input-output 
relationship between products, a business output will become another enterprise inputs, that is, intermediate inputs. The so-called intermediate input effect refers to the core enterprise-related upstream and downstream enterprises together with the layout of the economic effects.

\subsection{Labor - sharing effect}

Industrial enterprises focus on the layout, to attract a large number of specialized labor, the formation of large-scale specialized labor market, so as to obtain labor-sharing effect. The effect of labor-sharing effect on the reduction of pollution emissions is mainly reflected in the following aspects. First, it is conducive to increasing the general labor force proficiency, improve labor productivity and energy efficiency, to achieve energy conservation and reduce pollution emissions. Second, is conducive to saving labor costs, the cost savings for additional capital and technology investment, thereby reducing energy consumption and pollution emissions. Third, it is conducive to the cultivation of specialized talents, improve science and technology and innovation ability, thereby reducing energy consumption and pollution emissions.

\subsection{The measurement model, variables and data}

\subsection{The variables and data description}

Industrial agglomeration (agg) can produce economies of scale, economies of scope. The knowledge spillovers generated by industrial agglomeration can accelerate technological innovation and product innovation. At the same time, industrial agglomeration also produces environmental externality. In this paper, the location of the business district to measure the measurement of industrial agglomeration in various regions of Guangdong Province.

The intensity of energy consumption (energy) refers to the amount of energy consumed per unit of industrial added value, in tons of standard coal per ten thousand yuan. With the consumption and use of energy, it will produce a variety of pollution emissions, such as smoke dust, sulfur dioxide. As the number of energy sources used in the industrial production process is not uniform, the intensity of energy consumption will affect the intensity of pollution emissions. This paper chooses the amount of energy consumption per unit of industrial added value to measure the intensity of energy consumption, the relevant data from the Guangdong Statistical Yearbook.

Industrial structure upgrade (indstr) is through structural effects on the intensity of pollution emissions have an impact, generally believed that in the process of economic development, industrial upgrading can only rely on resource consumption, often accompanied by technological level, the proportion of pollution-intensive industries Decline, the service industry, knowledge-intensive industries such as the proportion of tertiary industry increased, which will reduce the level of pollution emissions or emissions intensity. In this paper, we choose the proportion of the pollution-intensive enterprises to the industrial added value to reflect the change of the industrial structure.

The degree of openness of the industry (open) has a positive effect on reducing pollution emissions. Foreign direct investment will generally be high, while 
foreign-funded enterprises have advanced production technology and advanced management methods to achieve higher energy efficiency, and foreign-funded enterprises generally have higher environmental standards, have an advantage in the energy-saving Row. In addition, the high degree of openness of the industry, the level of exports will generally be higher, and because more developed countries have enacted energy clean-up bill, the manufacturing export products, the level of pollution emission requirements, to promote export-oriented enterprises to adopt clean technology production.This paper uses the proportion of foreign-invested enterprises as the substitute of the total output value of the industry to measure the degree of industry openness.

\subsection{Model settings}

Common panel data models include mixed-effects models, fixed-effects models, and random-effects models. The model forms are:

Dust $_{\mathrm{ij}}=\alpha+\beta_{1}$ Agg $_{\mathrm{ij}}+\beta_{2}$ Indstrij $_{\mathrm{ij}}+\beta_{3}$ Enengy $_{\mathrm{ij}}+\beta_{4} \mathrm{Open}_{\mathrm{ij}}+\varepsilon_{\mathrm{ij}}$

Dust $_{\mathrm{ij}}=\alpha_{\mathrm{i}}+\beta_{1} \mathrm{Agg}_{\mathrm{ij}}+\beta_{2}$ Indstrij $_{\mathrm{ij}}+\beta_{3}$ Enengy $_{\mathrm{ij}}+\beta_{4}$ Open $_{\mathrm{ij}}+\varepsilon_{\mathrm{ij}}$

Dust $_{\mathrm{ij}}=\alpha_{\mathrm{i}}+\beta_{1}$ Agg $_{\mathrm{ijj}}+\beta_{2}$ Indstr $_{\mathrm{ij}}+\beta_{3}$ Enengy $_{\mathrm{ij}}+\beta_{4} \mathrm{Open}_{\mathrm{ij}}+\varepsilon_{\mathrm{ij}}$

In the equation (1), $\alpha$ is fixed, but $\alpha_{i}$ is a random variable in equation (2) and Eq. (3). $\alpha_{\mathrm{i}}$ in equation(2) is related to the explanatory variables Agg, Indstr, Energy, Open. $\alpha_{\mathrm{i}}$ in Eq. (3) is independent of the explanatory variables Agg, Indstr, Energy, Open. I represents a region of Guangdong Province, $j$ represents a year, $\alpha_{i}$ represents a constant term, Dust represents dust emission intensity, Agg represents industrial agglomeration, Indstr represents industrial structure, Energy represents energy consumption intensity and Open represents openness.

In order to determine the form of the panel data model, this paper needs $\mathrm{F}$ test and Hausman test. The test results show that we should choose fixed-effect model form, the specific test results refer to the following table:

Table 1: Model Determination Test

\begin{tabular}{|l|l|l|l|}
\hline Testing method & Null hypothesis & Statistic value & test result \\
\hline F test & Mixed effect model & 63.11 & Reject \\
\hline Hausman test & $\begin{array}{l}\text { Random effect } \\
\text { model }\end{array}$ & 281.92 & Reject \\
\hline
\end{tabular}

Therefore, the specific form of the panel data model chosen in this paper is:

Dust $_{\mathrm{ij}}=\alpha_{\mathrm{i}}+\beta_{1} \mathrm{Agg}_{\mathrm{ij}}+\beta_{2}$ Indstr $_{\mathrm{ij}}+\beta_{3}$ Enengy $_{\mathrm{ij}}+\beta_{4}$ Open $_{\mathrm{ij}}+\varepsilon_{\mathrm{ij}}$

$\alpha_{\mathrm{i}}$ is related to the explanatory variables Agg, Indstr, Energy, Open.

\subsection{Measurement Test}

In order to avoid false regression or false regression, this paper first needs to test the unit root of the explanatory variable and the explanatory variable to ensure that the data is stationary. Then, under the premise that the explanatory variable and the interpreted variable have the same order, the cointegration test is carried out to test whether the explanatory variables have the long-term stable relationship with the explanatory variables. Finally, the regression estimation is performed. 
Table2: Unit Root Test

\begin{tabular}{|l|l|l|}
\hline & LLC(P) & F-ADF(P) \\
\hline Dust & 0.0000 & 0.0016 \\
\hline Agg & 0.0000 & 0.0044 \\
\hline Indstr & 0.0000 & 0.0000 \\
\hline Energy & 0.0000 & 0.0381 \\
\hline Open & 0.0000 & 0.0000 \\
\hline
\end{tabular}

From the table above, Dust, Agg, Indstr, Engergy, open all pass the first-order differential unit root test at the $5 \%$ confidence level, so the data is stationary.

Since the explanatory variables Dust and the explanatory variables Agg, IndStr, Energy, Open are all single-order, the cointegration test can be carried out in this paper. The concrete test results are as follows:

Table 3: Cointegration Test

\begin{tabular}{|l|l|l|l|}
\hline Testing method & Statistic name & Statistic value & $\mathrm{P}$ \\
\hline Kao test & ADF & -3.53 & 0.0018 \\
\hline
\end{tabular}

$\mathrm{P}$ is less than 0.05, so Dust, Agg, Indstr, Energy, Open between the long-term stability. On the basis of unit root and cointegration test, this paper makes OLS estimation Table 4: Model Test Results

\begin{tabular}{|l|l|l|l|}
\hline Explanatory variables & coefficient & T Statistics & $\mathrm{p}$ \\
\hline Agg & -117.39 & -2.034374 & 0.0417 \\
\hline Energy & 57.99 & 6.926858 & 0.0000 \\
\hline Indstr & 415.12 & 2.139171 & 0.0337 \\
\hline Open & 57.28 & 0.683399 & 0.4952 \\
\hline Number of samples & 210 & P(F) & 0.0000 \\
\hline R-squared & 0.700591 & Adjusted R-squared & 0.634884 \\
\hline
\end{tabular}

\section{Analysis of result}

\subsection{Industrial agglomeration}

The coefficient of industrial agglomeration factor is negative, and is significant at the $5 \%$ confidence level, which proves that the increase of industrial agglomeration degree will bring down the intensity of industrial dust emission in Guangdong, Pollution emissions have a positive impact.

\subsection{Industrial structure}

The coefficient of industrial structure factor is positive and is significant at the $5 \%$ confidence level. This proves that the structural factor of the industry has a negative effect on the reduction of industrial pollution emissions in Guangdong, that is, the higher the proportion of polluting industries, the stronger the emission intensity of industrial dust Large, which is consistent with the theoretical expectations.

\subsection{Energy consumption}

The coefficient of energy consumption structure factor is positive, and the energy consumption intensity factor is significant at the $5 \%$ confidence level. This shows that energy consumption intensity factors have a positive impact on the intensity of industrial soot emissions, that is, the greater the energy consumption per unit of output, the higher the intensity of industrial soot emissions, which is the same as 
theoretical expectations.

\subsection{Degree of opening to the outside world}

The coefficient of industry openness factor is positive, not significant at the $5 \%$ confidence level. Indicators of the degree of openness of the industry (foreign-invested enterprises accounted for the proportion of industrial output value) in the 2005-2014 data on smoke and dust emissions have no clear impact. From the data of 2005-2014, it can be seen that the proportion of foreign-invested enterprises' output value in industrial production decreased year by year. However, we can't say that the technical level and energy utilization level of the corresponding industries declined as the industry's opening degree decreased. Therefore, the degree of openness of the industry from the 2005-2014 data, the impact of smoke and dust emission intensity can't be determined.

\subsection{Conclusion}

Based on the above results, first of all, how to make rational use of industrial agglomeration and realize the effective reduction of pollution emission intensity through optimization of industrial spatial distribution is the issue that the Chinese government should pay special attention to and focus on. In addition, the government should pay attention to how to coordinate the industrial space layout strategy and regional development strategy. Moreover china should speed up the transformation and upgrading of industry, and transform the manufacturing industry from relying on resources and labor to relying on capital and technology, from factor-driven industry structure to innovation-driven industry structure. Last but not least, Guangdong should attach importance to the intensity of energy consumption, promote technological progress in industry, and reduce pollutant emission from the source of energy consumption in the process of promoting industrial upgrading and inter-regional industrial transfer.

\section{References}

[1] Krugman P. Increasing returns and economic geography[J].Journal of Political Economy.1991.(88):483-499.

[2] Zeng D Z, Zhao L. Pollution havens and industrial agglomeration[J]. Journal of Environmental Economics and Management. 2009

[3] Yang R F. Industrial Agglomeration, Foreign Direct Investment and Environmental Pollution[J]. Economic management. 2015

[4] Li R F. An Empirical Analysis of the Relationship between Manufacturing Agglomeration and Air Pollution in China [D]. Henan Normal University,2012

[5] Zeng D Z, Zhao L. Pollution havens and industrial agglomeration[J]. Journal of Environmental Economics and Management. 2009

[6] Li C X. An Empirical Study on the Relationship between Energy Consumption and Environmental Pollution [J]. Coal Economic Research. 2009

[7] Yuan Y J. The Internal Relationship between Industrial Agglomeration, Technological Innovation and Environmental Pollution [J] Scientific research. 2015 [8] Abdul Jalil. Environment Kuznets Curve for CO2 Emissions: A Cointergration Analysis for China[J].Energy Policy. 2009 
[9] Cao R F. A Study on the Influence of Xin Jiang province's Industry Agglomeration on Environment[D]. Xinjiang University. 2011 